\title{
Edukasi Deteksi Dini Stroke Pada Komunitas Diabetes Di Kota Mataram
}

\author{
Ilsa Hunaifi*1, Herpan Syafii Harahap ${ }^{1}$, Joko Anggoro² ${ }^{2}$ I Gede Yasa Asmara², \\ Rina Lestari ${ }^{3}$, Dewi Suryani ${ }^{4}$. \\ ${ }^{1}$ Departemen Neurologi FK Universitas Mataram/RSUD Propinsi NTB \\ ${ }^{2}$ Departemen Ilmu Penyakit Penyakit Dalam FK Universitas Mataram/RSUD Propinsi NTB \\ ${ }^{3}$ Departemen Ilmu Penyakit Paru FK Universitas Mataram/RSUD Propinsi NTB \\ ${ }^{4}$ Departemen Mikrobiologi FK Universitas Mataram
}

\section{Article history}

Received: 26 Februari 2019

Revised: 01 Maret 2019

Accepted: 04 Maret 2019

*Corresponding Author:

Ilsa Hunaifi

FK Universitas Mataram, Mataram, Indonesia

Email: ilsahunaifi@unram.ac.id

\begin{abstract}
Stroke remains one of the major causes of death and disability in Indonesia with a mortality and disability rate of $15 \%$ and $65 \%$, respectively. Diabetes is known as a modifiable risk fator on stroke. Promptly identifying the symptoms of stroke is crucial as it leads to faster treatment and minimize brain damage. However, most patients are unaware of the early warning signs and symptoms of stroke. Therefore, providing education on early detection of stroke for patients with diabetes is essential as it may improve awareness on early signs of stroke hence allow patients to seek early treatment and later reduce the impact of the disease. The aim of this community education is to increase awareness of stroke and provide information on early signs and prevention of stroke among patients with diabetes.To achieve the aim of this community education include provide a talk/presentation on early sign of stroke and healthy life style for diabetes patient and evaluation of process. Evaluation of the community education was conducted through a pre and posttest to all participant on the related issue. Approximately 18 diabetes patients took part in this community education. The pre-test average score of participants was $73.33 \%$. After providing education on stroke early detection, the participants' average score increased to 86.67 or increased by $18 \%$. Education for early detection of stroke among Diabetes patients increased participants' understanding of the symptoms and early signs of stroke.
\end{abstract}

Key Word: Stroke, Diabetes Mellitus

\section{Abstrak}

Di Indonesia, stroke merupakan penyebab kematian dan kecacatan utama di seluruh rumah sakit dengan angka kematian sekitar $15 \%$ dan tingkat kecacatan mencapai $65 \%$. Salah satu faktor risiko stroke yang dapat dimodifikasi adalah diabetes melitus. Gejala stroke dini sangat menentukan dalam kecepatan pengobatannya. Permasalahannya saat ini penderita stroke datang terlambat untuk mencari pengobatan di RS. Penderita diabetes merupakan penderita dengan resiko terjadinya stroke. Untuk meningkatkan keberhasilan dan mencegah kecacatan pada pasien DM maka diperlukan penyuluhan gejala-gejala dini stroke pada komunitas diabetes. Metode edukasi menggunakan penyuluhan yang diawali dengan pemberian pre test untuk mengetahui pengetahuan awal peserta terkait stroke dan diakhiri dengan post test untuk menilai kemajuan dan pemahaman pengetahuan peserta. Peserta sebanyak 18 orang. Pada pretest didapatkan nilai awal rata-rata peserta sebesar 73.33. Materi edukasi diberikan dengan metode ceramah dengan menggunakan powerpoint dan diakhiri dengan tanya jawab. Pada sesi akhir peserta diberikan kembali post test dan didapatkan nilai rata-rata peserta meningkat menjadi 86.67 atau mengalami peningkatan sebesar $18 \%$.dukasi deteksi dini stroke pada komunitas Diabetes melitus meningkatkan pemahaman peserta terhadap gejala dan tanda dini dari stroke.

Kata Kunci : Stroke, Diabetes Mellitus 


\section{PENDAHULUAN}

Stroke merupakan penyebab kematian terbesar keempat di Amerika Serikat. Diperkirakan 6,8 juta orang terkena stroke, 610 ribu kasus stroke baru setiap tahunnya dan $87 \%$ adalah stroke iskemik (Go, Mozaffarian et al., 2013). WHO (World Health Organization) memperkirakan sekitar 15 juta orang terkena stroke di seluruh dunia, 5 juta meninggal dan sisanya mengalami kecacatan permanen (WHO, 2013). Di Indonesia, Departemen Kesehatan melaporkan stroke merupakan penyebab kematian dan kecacatan utama di seluruh rumah sakit di Indonesia dengan angka kematian sekitar 15\% dan tingkat kecacatan mencapai 65\% (Depkes, 2013(b)). Data di Rumah Sakit Umum Daerah (RSUD) Dr. Soetomo tahun 2012 menunjukkan stroke iskemik mencapai 68,94\% dengan mortalitas yang cukup tinggi yakni 28,76\% (Islam, 2013).

Faktor resiko stroke terbagi menjadi tiga yakni tidak bisa dimodifikasi, dapat dimodifikasi dan potensial dapat dimodifikasi. Faktor yang dapat dimodifikasi yang sudah terdokumentasi dengan baik antara lain Diabetes Mellitus (Goldstein, Bushnell et al, 2011). Diabetes Melitus memicu terjadinya disfungsi endotel yang akan menyebabkan proses aterosklerosis. Perubahan awal dari endotel merupakan kunci terjadinya aterosklerosis. Perubahan tersebut adalah peningkatan permeabilitas endotel terhadap lipoprotein yang dimediasi oleh NO (Nitrit Oxide), upregulation dari molekul adhesi endotel dan migrasi leukosit pada dinding endotel yang dimediasi oleh LDL (Low Density Lipoprotein) yang teroksidasi. Penurunan kadar NO di endotel mengakibatkan efek proinflamasi, protrombotik dan prokoagulan yang akan mengubah struktur pembuluh darah. Kemudian terjadi reaksi inflamasi yang diikuti proliferasi sel otot polos dan penebalan dinding pembuluh darah (Han, Bae et al, 2011; Hisham, Bayraktutan et al, 2012). Aterosklerosis mengakibatkan proses thrombosis baik intracranial maupun ekstrakranial (Caplan, 2009). Penurunan aliran darah ke otak merupakan kejadian utama pada stroke akut. Hal tersebut akan mengakibatkan adanya parenkim otak yang segera akan mengalami kematian (core) dan daerah yang potensial dapat mengalami perbaikan (penumbra) (Deb, Sharma et al, 2010). Gejala stroke dapat dibagi menjadi gejala pada sirkulasi otak sisi anterior dan sirkulasi otak sisi posterior. Gejala terbanyak stroke akibat thrombosis pada sirkulasi otak bagian anterior antara lain hemiparesis atau monoparesis, hemisensory, sakit kepala dan afasia, sedangkan gejala akibat thrombosis pada sirkulasi posterior antara lain vertigo, gangguan lapang pandang, penurunan kesadaran, dan hemiparesis (Greenberg, Aminoff et al, 2012).

Gejala stroke dini sangat menentukan dalam kecepatan pengobatannya. Permasalahannya saat ini penderita stroke datang terlambat untuk mencari pengobatan di RS. Penderita Diabetes merupakan penderita dengan resiko terjadinya stroke. Untuk meningkatkan keberhasilan dan mencegah kecacatan pada pasien DM maka diperlukan penyuluhan gejalagejala dini stroke pada komunitas diabetes 


\section{METODE}

Edukasi deteksi dini stroke pada komunitas diabetes dilakukan dengan berbagai metode. Untuk mengetahui pengetahuan awal peserta diberikan pre test yang berisi tanda dan gejala stroke, apa yang harus dilakukan apabila terkena stroke. Peserta kemudian diberikan edukasi dengan memberikan materi-materi terkait stroke berupa definisi stroke, tanda dan gejala stroke serta apa yang harus dilakukan apabila terkena stroke. Edukasi kedua berupa langkah-langkah dan tips hidup sehat pada penderita diabetes melitus.

Materi edukasi disampaikan dengan menggunakan bahasa yang sederhana dilengkapi dengan contoh gambar dan disajikan dalam bentuk power point. Setelah penyampaian materi diikuti dengan sesi diskusi dan tanya jawab. Pada akhir sesi edukasi, peserta diberikan post test untuk mengetahui tingkat pengetahuan akhir peserta terhadap materi edukasi.

\section{HASIL DAN PEMBAHASAN}

Edukasi deteksi dini stroke dihadiri oleh 18 orang anggota komunitas diabetes di kota Mataram. Kegiatan dilaksanakan di Aula Rumah Sakit Umum Propinsi NTB Jalan Pejanggik Mataram. Peserta terdiri dari 14 orang perempuan dan 4 orang laki-laki.

Kegiatan edukasi ini di bagi menjadi 4 sesi. Sesi pertama registrasi dan pembukaan. Sesi kedua pre test, sesi ketiga berupa edukasi dengan metode penyuluhan dan sesi keempat berupa tanya jawab dan post test. Pre test pada peserta bertujuan untuk mengetahui pengetahuan awal peserta terhadap gejala dan tanda dini dari stroke. Pada pre test ditanyakan mengenai definisi, gejala dan tanda stroke. Pada sesi edukasi berupa penyuluhan, terdapat 2 topik penyuluhan yakni deteksi dini gejala dan tanda stroke dan kedua tentang tips hidup sehat pada penderita diabetes. Metode penyampaian materi dengan cara memaparkan materi dengan media power point dan diikuti dengan sesi tanya jawab. Pada akhir sesi peserta diberikan post test untuk mengetahui tingkat pengetahuan akhir peserta terhadap materi edukasi yang diberikan dengan memberikan pertanyaan yang sama dengan pre test. Hal ini ditujukan untuk mengetahui peningkatan pengetahuan peserta setelah diberikan materi edukasi.

Pada pre test didapatkan skor rata-rata peserta sebesar 73.33. $33.3 \%$ peserta mendapatkan nilai pre test dibawah rata-rata. Pada akhir sesi edukasi, didapatkan skor post test sebesar 86.67 dan terjadi kenaikan sebesar 13.34 poin atau $18 \%$ pengetahuan peserta dalam menyerap informasi yang disampaikan dalam sesi edukasi penyuluhan dan tanya jawab. Hal ini menunjukkan edukasi dengan penyuluhan terhadap tingkat pengetahuan peserta berjalan efektif.

Penyuluhan adalah usaha memberikan keterangan, penjelasan, petunjuk, bimbingan, tuntunan kepada setiap orang sehingga dapat memecahkan masalah dan meningkatkan kualitas hidupnya. Penyuluhan kesehatan bertujuan untuk merubah cara berfikir dan perilaku kesehatan. Tujuan utama penyuluhan kesehatan untuk meningkatkan pengetahuan sehingga diharapkan terjadinya perubahan perilaku (Wulansari, 2019). Pada penyuluhan dan edukasi deteksi dini 
gejala dan tanda stroke pada komunitas diabetes ini diharapkan peningkatan pengetahuan terhadap stroke mampu merubah perilaku penderita diabetes melitus untuk segera mencari pengobatan apabila terdapat gejala dan tanda stroke sehingga angka kematian dan kecacatan akibat stroke dapat diturunkan. Menurut riset dasar kesehatan Departemen Kesehatan Republik Indonesia tahun 2013, angka kejadian stroke meningkat dari 8.3 per 1000 penduduk pada tahun 2007 menjadi 12.1 per 1000 penduduk pada tahun 2013. Disamping itu prevalensi diabetes melitus meningkat dari $1.1 \%$ penduduk pada tahun 2007 meningkat menjadi $2.1 \%$ penduduk pada tahun 2013. Prevalensi stroke banyak didapatkan pada masyarakat dengan tingkat pendidikan yang rendah dan banyak terjadi pada masyarakat di perkotaan dibandingkan di pedesaan (Depkes, 2013(a)).

Penyuluhan dan edukasi dapat dilakukan dengan berbagai cara antara lain pendekatan perorangan dan pendekatan kelompok. Pendekatan melalui kelompok sangat efektif apabila anggotanya berjumlah > 15 orang dan banyak dilakukan dengan metode ceramah atau seminar. Pemberian penyuluhan dengan metode ceramah merupakan metode yang alamiah dan mudah dilakukan. Dengan berbicara, maka pemateri dapat berinteraksi langsung dengan peserta dan supaya penyuluhan dapat berjalan efektif dapat dibantu dengan bantuan slide, gambar dan poster. Penyuluhan yang baik dapat berdampak terhadap perilaku sehingga menjadi lebih baik (WHO, 1988). Pada penyuluhan ini, nampak bahwa ceramah yang dilakukan berjalan efektif serta tingkat rata-rata pengetahuan peserta meningkat yang ditandai dengan peningkatan nilai post test.
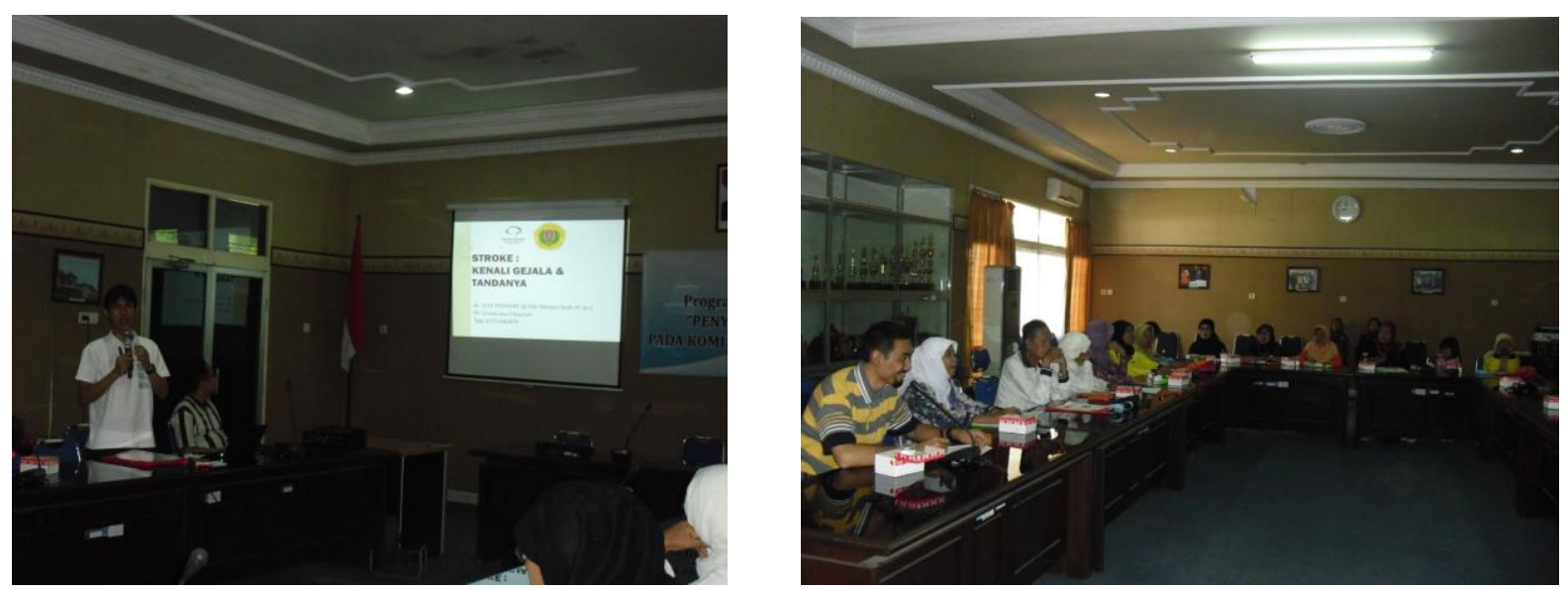

Gambar 1. Suasana Saat pemberian Edukasi 


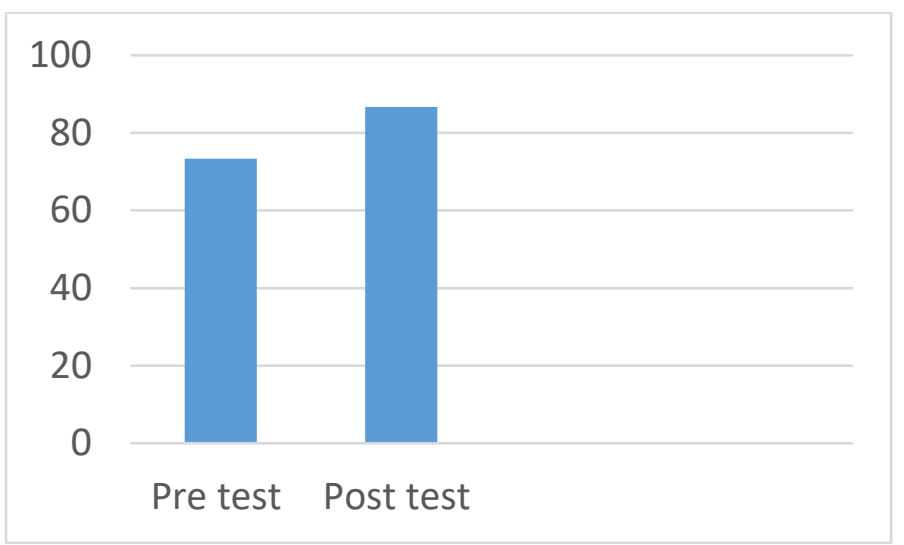

Gambar 2 Grafik Perbandingan Nilai Rata-rata Pre dan Post test

\section{KESIMPULAN}

Edukasi dengan metode ceramah tentang deteksi dini stroke pada komunitas diabetes melitus meningkatkan pemahaman terhadap gejala dan tanda dini stroke sehingga meningkatkan kesadaran untuk segera mendapatkan pertolongan untuk mencegah kecacatan dan kematian akibat stroke. Cakupan edukasi yang lebih luas kepada berbagai komunitas sehingga dapat memberikan pengetahuan kesehatan dan perubahan perilaku yang lebih baik untuk mencegah kecacatan akibat stroke.

\section{Ucapan Terima Kasih}

Ucapan terima kasih disampaikan kepada seluruh team pengabdian masyarakat, Direktur RSUD Propinsi NTB yang memberikan fasilitas ruangan penyuluhan dan koordinator komunitas diabetes di kota Mataram.

\section{DAFTAR PUSTAKA}

Caplan RL, 2009, Caplan's Stroke A Clinical Approach, Saunders Elsevier : Philadelphia, pp. 3-16

Deb P, Sharma S, Hassan KM., 2010. Pathophysiologic Mechanisms of Acute Ischemic Stroke: An Overview with Emphasis on Therapeutic Significance Beyond Thrombolysis. Pathophysiology 17 : 197-218

Departemen Kesehatan Republik Indonesia, 2013(a). Hasil Riskesdas 2013, www.depkes.go.id, diakses tanggal 5 Januari 2019

Departemen Kesehatan Republik Indonesia, 2013 (b). Menkes Lakukan Soft Opening Rumah Sakit Pusat Otak Nasional, www.depkes.go.id, diakses tanggal 5 Januari 2019.

Go AS, Mozaffarian D, Roger VL, Benjamin EJ, Berry JD, Borden WB, Bravata DM, Dai S, Ford ES, Fox CS, Franco S, Fullerton HJ, Gillespie C, Hailpern SM, Heit JA, Howard VJ, Huffman MD, Kissela BM, Kittner SJ, Lackland DT, Lichtman JH, Lisabeth LD, Magid D, Marcus GM, Marelli A, Matchar DB, McGuire DK, Mohler ER, Moy CS, Mussolino ME, Nichol G, Paynter NP, Schreiner PJ, Sorlie PD, Stein J, Turan TN, 
Virani SS, Wong ND, Woo D, Turner MB, 2013. Heart Disease and Stroke Statistics2013 update: a Report from The American Heart Association, Circulation 127 : e6e245

Goldstein LB, Bushnell CD, Adams RJ, Appel LJ, Braun LT, Chaturvedi S, Creager MA, Culebras A, Eckel RH, Hart RG, Hinchey JA, Howard VJ, Jauch EC, Levine SR, Meschia JF, Moore WS, Nixon JV, Pearson TA, 2011. Guidelines for the Primary Prevention of Stroke : A Guidelines for Healthcare Professionals from American Heart Association/American Stroke Association. Stroke 42 : 517-584

Greenberg DA, Aminoff MJ, Simon RP, 2012. Clinical Neurology $8^{\text {th }}$ ed, McGrawHill Medical : New York pp. 384.

Han J, Bae HJ, Wong LKS, 2011. Pathophysiology and Mechanism Whereby Hypertension may cause Stroke. In : Aiyagi V, Gorelick PB (Eds), Hypertension and Stroke : Pathophysiology and Management, Humana Press : New York, pp.77-94

Hisyam NF, Bayraktutan U, 2012. Epidemiology, Pathophysiology, and Treatment of Hypertension in Ischaemic Stroke Patients. Journal of Stroke and Cerebrovascular Disease xx : 1-11

Islam MS, 2013. Acute Ischemic Stroke In Surabaya, In : Islam MS, Sani AF, Subadi I et al, (Eds). Postgraduate Course on Neurology and Rehabilitation Medicine, FK Unair : Surabaya, hal. 84

World Health Organization, 2013. The Atlas of Heart Disease and Stroke, Retrieved : August 31, 2013, from http://www.who.int/cardiovascular_disease

World Health Organization, 1988. Education for Health A Manual on Health Education in Primary Health Care, Retrieved : January 31, 2019, from http://www.who.int/iris/handle/10665/77769

Wulansari R, 2019. Strategi Penyuluhan Kesehatan, www.academia.edu, diakses tanggal 30 Januari 2019 